\title{
PENGGANTIAN SLING PADA MENARA TELEKOMUNIKASI RANGKA BAJA YANG DISUPPORT OLEH GUY WIRE
}

\author{
oleh : \\ Budi Satiawan \\ Teknik Sipil Universitas Muhammadiyah Jakarta \\ Email : budi.satiawan@umj.ac.id
}

\begin{abstract}
Abstrak : Berdasarkan hasil inspeksi awal dari fasilitas menara telekomunikasi rangka baja yang disupport oleh guy wire dengan ketinggian $86 \mathrm{~m}$ telah beroperasi selama labih kurang 30 tahun di area Kalimantan Timur diketahui telah terjadi penurunan integritas material yaitu korosi pada elemen struktur tower. Internal study perusahaan yang telah dilakukan meliputi kajian terhadap laporan jasa konsultan terdahulu (2013) beserta pengukuran kondisi geometeri tower terakhir serta hasil inspeksi korosi pada elemen struktur dari Menara telekomunikasi (2016) ditemukannya kondisi korosi pada sebagian besar elemen guy wire beserta aksesorisnya sehingga diperlukannya penggantian sling pada semua guy wire yang telah mengalamai korosi sebanyak 21 set yang terdapat pada elevasi $+70.9 \mathrm{~m}$ hingga 80.3m dari menara telekomunikasi. Analisa engineering diperlukan untuk memutuskan langkah yang tepat untuk menentukan metode penggantian semua sling yang terkorosi dimana langkah kerja ini akan tertuang di dalam dokumen metode kerja saat eksekusi (Special Working Procedure) sehingga resiko kegagalan struktur saat dilakukan pekerjaan penggantian sling dapat dimitigasi.
\end{abstract}

Kata Kunci : tower telekomunikasi rangka baja, sling, guy wire, korosi, analisa engineering

Abstract : Based on the results of preliminary inspections of steel truss telecommunication tower facilities supported by guy wire with a height of $86 \mathrm{~m}$ which has been operating for more than 30 years at East Kalimantan area, it is known that there has been a decrease in material integrity by corrosion on tower structure elements. The internal studies that have been carried out include a review of the previous consultant report (2013) along with measurements of the latest condition of the tower geometry as well as the results of corrosion inspections on the structural elements of the telecommunication tower (2016) was found corrosion conditions on most guy wire elements and their accessories so there were needed slings replacement on all guy wires that have corroded as many as 21 sets found at the elevation $+70.9 \mathrm{~m}$ to $80.3 \mathrm{~m}$ of telecommunication towers. Engineering analysis is needed to decide on the right step to determine the method of replacing all corroded slings in which the working steps will be specified in the Special Working Procedure document so the risk of structural failure when sling replacement work is mitigated.

Keywords: steel truss telecommunication tower, slings, guy wire, corrosion, engineering analysis

\section{Pendahuluan}

Pada tahun 2016, dari bagian Communication Dept. suatu perusahaan energi yang berada di area Kalimantan Timur meminta team engineering untuk melakukan perbaikan terhadap menara telekomunikasi yang saat itu masih beroperasi karena telah ditemukan kondisi dimana telah terjadi penurunan integrity dari struktur menara telekomunikasi yang disupport oleh guy wire. Permintaan ini didasari dari data konsultan yang pernah dilakukan pada tahun 2013 dan evaluasi dari tim Engineering Authority internal perusahaan yang dilakukan pada tahun 2016. 
Berdasarkan informasi yang diperoleh bahwa tower ini telah mengalami modifikasi strukutur, dimana pembangunan dilakukan pada tahun 1983 dengan ketinggian awal 70.9 m (section-1) dan kemudian pada tahun 2004 telah dilakukan modifikasi dimana ketinggian tower ditambah sehingga menjadi $80.3 \mathrm{~m}$ (section-2).

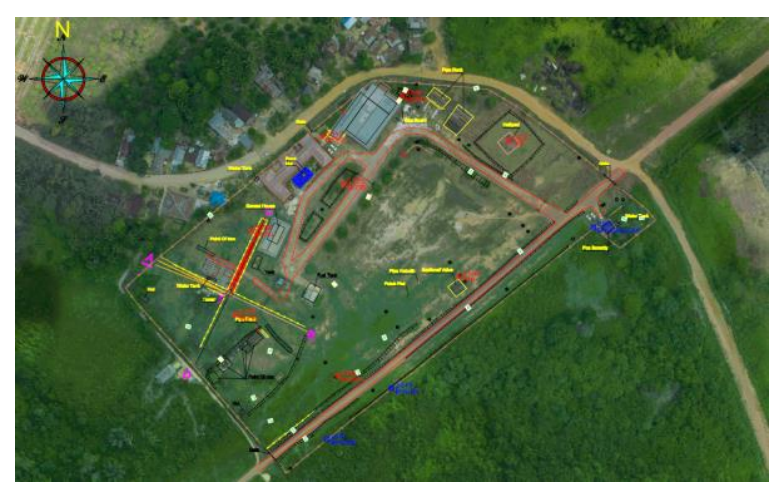

Gambar 1. Sitting Layout Menara Telekomunikasi

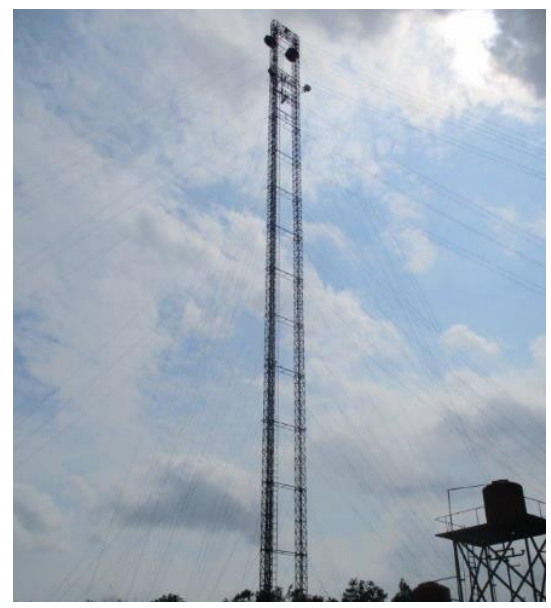

Gambar 2. Tampak Menara Telekomunikasi

Untuk penggantian semua material guy wire yang telah mengalami korosi perlu dilakukan perencanaan metoda kerja yang matang sehingga dapat memitigasi resiko kegagalan yang dapat terjadi pada struktur menara tersebut saat pekerjaan dilakukan.

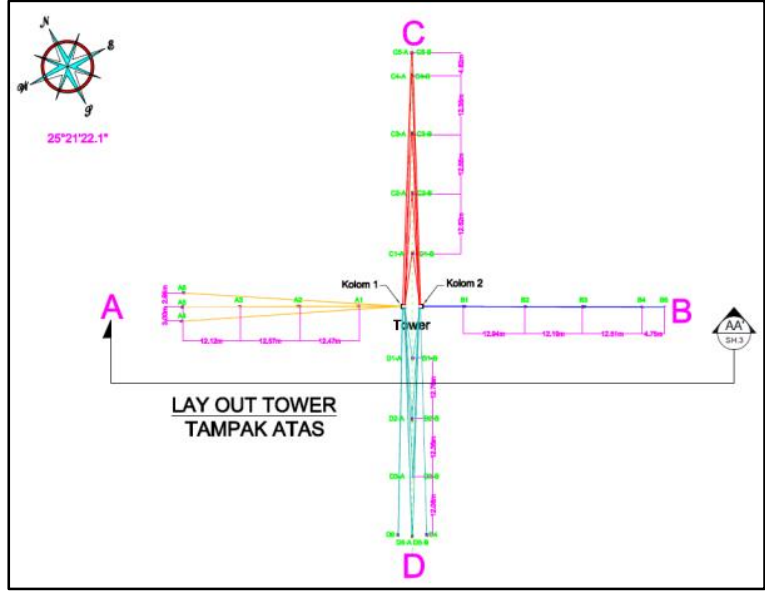

Gambar 3. Layout Menara

Telekomunikasi

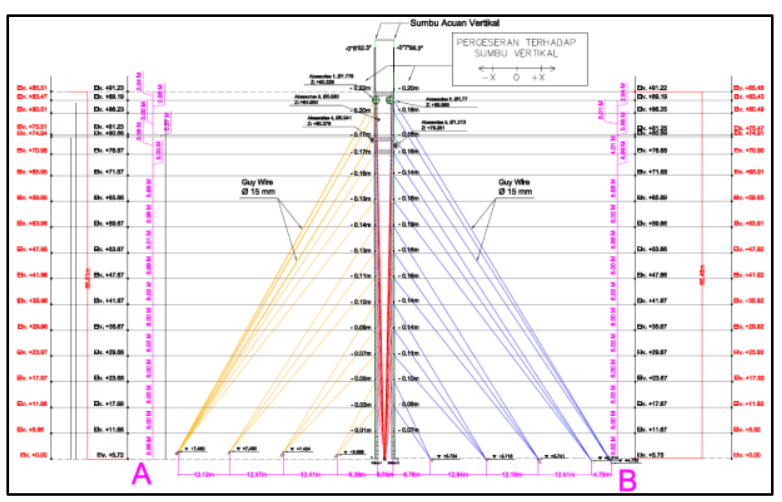

Gambar 4. Potongan A-A Menara telekomunikasi

\section{Tinjauan Pustaka}

Berdasarkan hasil evaluasi dari team Engineering Authority internal perusahaan yang telah dilakukan dengan mengevalusi semua data yang telah dikumpulkan diantaranya berasal dari Laporan jasa konsultan terdahulu (tahun 2013), gambar As built untuk menara telekomunikasi, laporan hasil pengukuran kondisi ketegakan dan puntir dari menara telekomunikasi serta hasil inspeksi kondisi material pada menara telekomunikasi yang diukur pada tahun 2016 dapat diperoleh beberapa rekomendasi yang sifatnya kritikal diantaranya adalah sebagai berikut:

1. Semua element guy wire yang terkoneksi pada section-2 dari menara telekomunikasi tidak sesuai dengan 
rekomendasi material yang disarankan oleh TIA-222-G-2005.

2. Kondisi guy wire yang terhubung pada tower section- 2 telah mengalami korosi berat, pergantian harus dilakukan secepatnya termasuk dengan aksesoris dari sling (shackle, wire clip, timble dan Turn buckle).

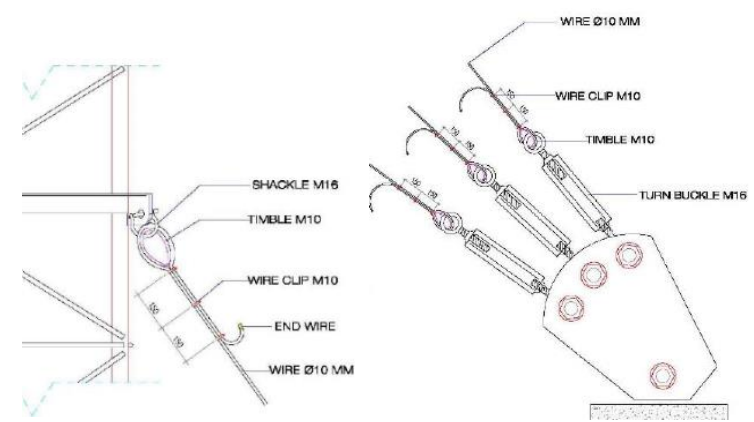

Gambar 5. Guy Wire \& Aksesoris

Perhitungan besaran puntir (twist) dan ketegakan (plumb) yang terjadi dari geometri menara telekomunikasi dengan bentuk kotak dilakukan berdasarkan rujukan dari TIA-222-G-2005 (gambar 6).

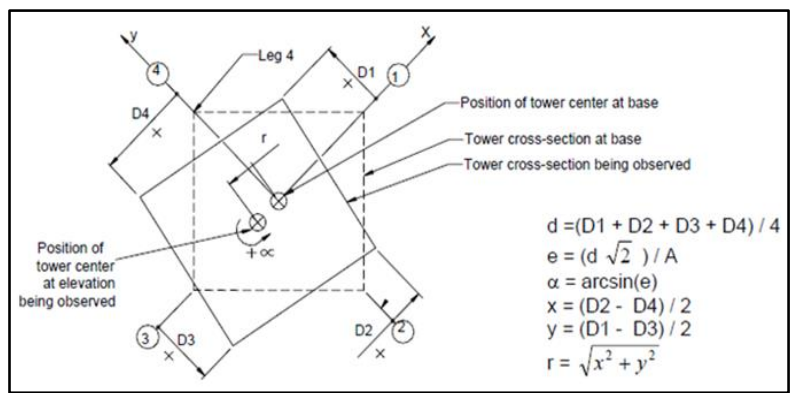

Gambar 6. Perhitungan twist dan plumb TIA-222-G-2005

Berdasarkan perhitungan untuk besaran dari kondisi puntir dan ketegakan dari geometri tower sisi- 1 dan tower sisi- 2 maka akan tersaji seperti pada tabel-1 dan tabel- 2 berikut.
Tabel 1. Besaran puntir dan ketegakan tower sisi-1

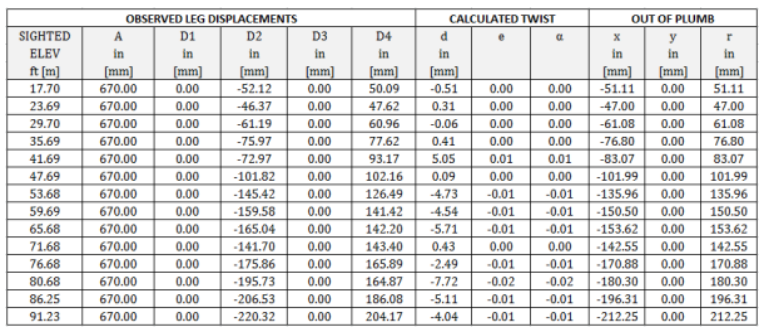

Tabel 2. Besaran puntir dan ketegakan tower sisi-2

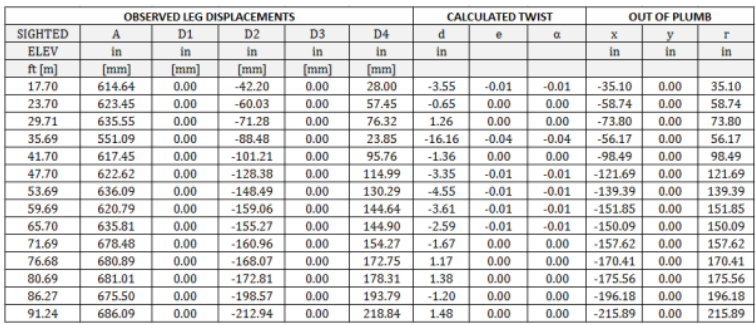

Batasan ijin dari puntir dan ketegakan berdasarkan TIA-222-G-2005 adalah sebagai berikut:

- Batasan maximum puntir yang diijinkan pada tiap ketinggian $10 \mathrm{ft}(3 \mathrm{~m})$ adalah 0.5 dan pada total ketinggian struktur adalah $5^{\circ}$.

- Batasan nilai plumb untuk tower dengan ketinggian, $\mathrm{H}=83.5 \mathrm{~m}$ adalah $0.25 \% \mathrm{x}$ $83.5=208 \mathrm{~mm}$

Sehingga dengan mempertimbangkan kondisi puntir dan ketegakan tower serta lama masa pakai tower selama beroperasi serta tidak adanya data historical tower saat masa pembangunan maka diputuskan secara geometri dari tower masih dapat dipertahankan.

Jenis kabel guy wire yang direkomendasikan oleh TIA-222-G-2005 untuk material kabel adalah tipe gavanized steel guy strand sehingga material awal kabel pada section-2 yang mengalami korosi yang awalnya berupa tipe wire rope akan diganti sesuai rekomendasi tersebut.

TIA-222-G-2005 memberikan rekomendasi untuk besarnya gaya tarikan awal (initial 
tension) pada guy wire sebesar 7\% hingga $15 \%$ dari breaking strength yang dikeluarkan dari pabrikan kabel (strand) tersebut. Sesuai rekomendasi tersebut maka akan dilakukan penyesuaian dimensi sling berdasarkan besaran initial tension yang aman yang akan digunakan sebagai pengganti sling yang mengalami korosi.

\section{Metodologi Penelitian}

Dalam melakukan simulasi tahap penggantian sling maka untuk perhituangan analisa struktur dan analisa desain akan menggunakan software MSTower. Untuk perhitungan analisa desain akan digunakan peraturan TIA/EIA 222F dan American Institute of Steel Construction Inc. "Allowable Stress Design" AISC-ASD 1993. Kriteria desain yang digunakan sesuai dengan persyaratan desain TIA/EIA 222F adalah sebagai berikut:

- Defleksi $=\mathrm{H} / 200=427.35 \mathrm{~mm}$

- Twist : 0.5 derajat

- Sway : 0.5 derajat

Pembebanan yang bekerja meliputi beban vertikal, beban antena, beban angin $(100 \mathrm{~km} / \mathrm{jam}$ untuk analisa tegangan batang, support reaction dan pondasi, $70 \mathrm{~km} / \mathrm{jam}$ untuk perhitungan twist, sway dan displacement).

Prosedur analisis tower dilakukan dengan melakukan simulasi sesuai metode penggantian yang akan dilaksanakan di lapangan, yaitu dengan melepas guy wire satu persatu secara bergantian dan diganti dengan yang baru. Langkah-langkah proses perhitungan untuk simulasi penggantian guy wire ini dapat dilihat pada Flow Chart Analisis Tower berikut :

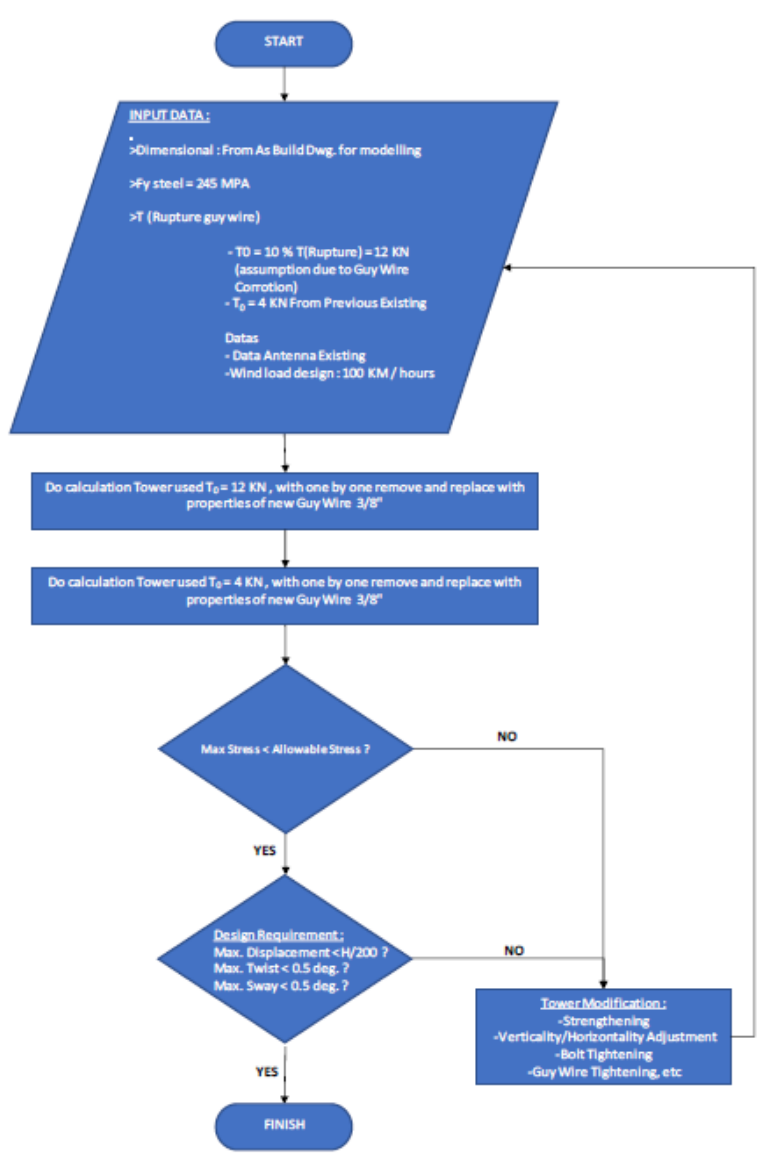

Gambar 7. Flow Chart Simulasi

\section{Analisis Dan Pembahasan}

Berdasarkan hasil analisis struktur menggunakan program MSTower.

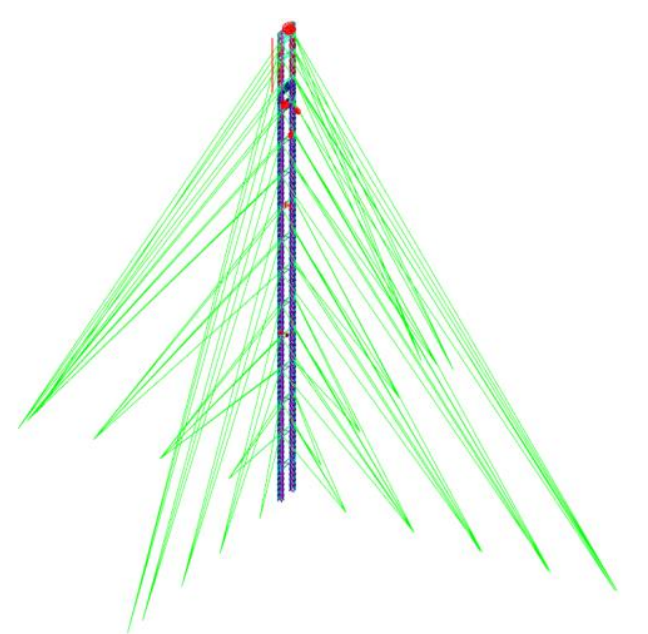

Gambar 8. Pemodelan Struktur Menara Tower 
Berdasarkan simulasi dari setiap langkah pekerjaan pelepasan dan pemasangan guy wire dapat diperoleh keluaran perhitungan berupa besaran rasio tegangan maksimum yang terjadi serta respon deformasi struktur (plumb, twist dan sway) seperti pada tabel-3 dan tabel-4. Kondisi dimana telah terjadi kejadian putusnya guy wire nomor D4-1 ikut dimodelkan sebagai tahap yang dipertimbangkan dalam langkah kerja dalam pemodelan simulasi struktur.

\section{Tabel 3. Tabulasi hasil perhitungan program struktur}

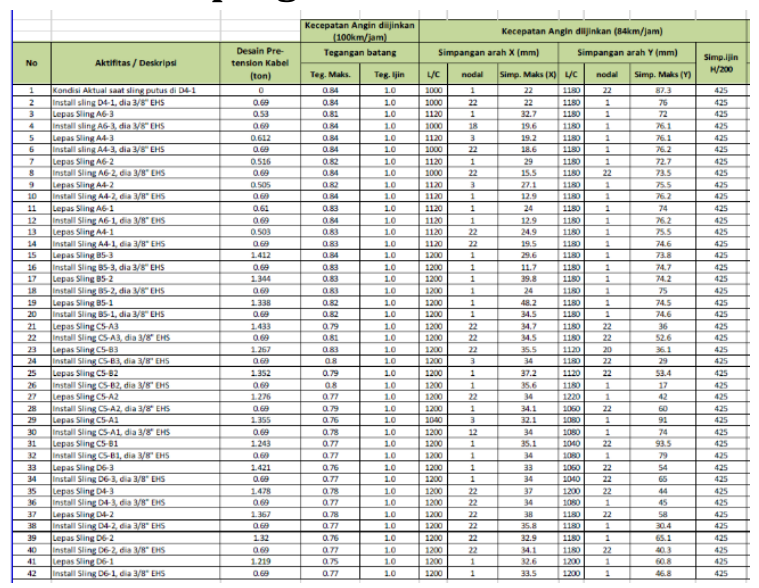

Tabel 4. Tabulasi hasil perhitungan program struktur

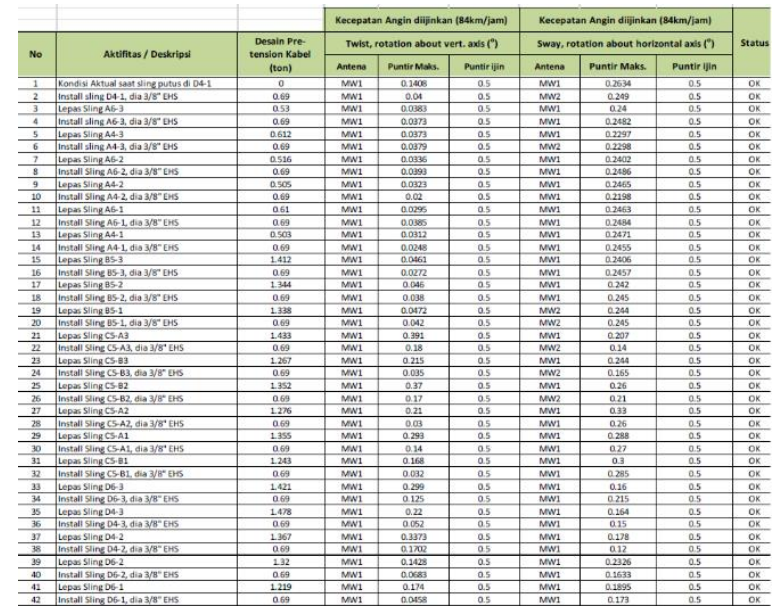

Berdasarkan dari hasil simulasi studi yang telah dilakukan maka dapat diperoleh secara berurutan tahapan untuk melepaskan dan pemasangan sling sesuai urutan analisis dan simulasi secara berurutan dengan aman adalah sebagai berikut:

-Pada Titik A: A4-1, A4-2,A4-3, A6-1, A6-2, A63

-Pada Titik B: B5-1, B5-2, B5-3

-Pada Titik C: C5-A1, C5B1, C5-A2, C5-B2, C5-A3, C5-B3, D6-1,D4-1, D6-2,D4-2,D6-3, D4-3

Dari hasil analisis saat simulasi pergantian sling (tahap demi tahap) dengan total sebanyak 21 sling diperoleh kondisi kritis sebagai berikut:

- Tegangan maksimum pada member tower sebesar 0,84 lebih rendah dari tegangan ijin maksimum $(1,00)$

- Twist maksimum sebesar 0,040 lebih rendah dari twist ijin maksimum $\left(0,5^{\circ}\right)$

- Sway maksimum sebesar $0,249^{\circ}$ lebih rendah dari sway ijin maksimum $0,5^{\circ}$.

Pada saat kondisi penggantian guy wire disarankan menggunakan guy wire dengan ukuran diameter 3/8", karena dengan penggunaan guy wire dia. $3 / 8$ " mm dan nilai $\mathrm{T} 0=6,9 \mathrm{KN}$, akan diperoleh rasio tegangan yang terjadi pada member Menara telekomunikasi yang lebih kecil jika dibandingkan menggunakan guy wire diameter $16 \mathrm{~mm}$ dengan $\mathrm{T} 0=12 \mathrm{KN}$ dikarenakan tower akan terbebani oleh nilai T0 yang besar sehingga tegangan awal yang akan bekerja pada tower juga akan semakin besar.

Dengan terpenuhinya semua kriteria desain maka langkah pekerjaan ini akan digunakan dalam rencana tahap eksekusi nantinya yang akan tertyang dalam suatu dokumen metoda kerja / SWP (Special Work Procedure). Dimana di dalam SWP tersebut mengatur langkah kerja team construction mulai dari persiapan, eksekusi hingga penyelesaian eksekusi. Dimana langkah kerja dari tahap eksekusi tersebut merupakan uraian tahaptahap simulasi dalam pemodelan struktur yang telah dilakukan. 
Selama dilakukan pekerjaan pelepasan dan pengencangan guy wire, kondisi geometri dari ketegakan tower selalu dimonitor menggunakan bantuan tim survey untuk memastikan tidak ada gerakan yang berlebihan dari tower. Melakukan pengukuran besaran initial tension (T0) ari setiap guy wire yang terpasang agar sesuai dengan T0 rencana yaotu sebesar $690 \mathrm{~kg}$ pada guy wire, dengan menggunakan alat tension meter yang telah terkalibrasi. Pekerjaan pengencangan dan pengendoran guy wire dapat dilakukan dengan memutar turnbuckle, sampai didapat tegangan T0 yang diinginkan terbaca pada tension meter.

\section{Kesimpulan}

Pada kondisi awal dimana guy wire D 4-1 putus dengan menggunakan kecepatan angin $100 \mathrm{~km} / \mathrm{jam}$ maka diperoleh bahwa struktural tower masih dalam kondisi aman (diasumsikan menggunakan T0 $=0 \mathrm{KN}$ ).

Dari hasil analisis saat simulasi pergantian sling (tahap demi tahap) dengan total sebanyak 21 sling diperoleh kondisi kritis yaitu tegangan maksimum pada member tower sebesar 0,84 $<1,00$ (tegangan ijin Maksimum). Twist maksimum yang terjadi adalah sebesar $0,04^{\circ}<0,5^{\circ}$ (twist ijin Maksimum) dan sway maksimum sebesar $0,249^{\circ}<0,5^{\circ}$ (sway ijin maksimum).

Sehingga dapat disimpulkan jika menara telekomunikasi masih dapat dikategorikan aman selama proses pekerjaan pergantian guy wire yang telah mengalami korosi dengan kondisi beban antena terpasang, beban angin yang bekerja dan juga saat menara telekomunikasi dioperasikan setelah dilakukannya penggantian sling.

\section{Daftar Pustaka}

American Institute of Steel Construction Inc. Allowable Stress Design AISC-ASD 1993
ANSI/TIA/EIA-222-F Structural Standards for Steel Antenna Towers and Antenna Supporting Structures, 1996

ANSI/TIA-222-G Structural Standard for Antenna Supporting Structures and Antennas, 2005

Badaruddin, 2016. Study \& Evaluation structural Integrity of Kutai Lama

PT. CURA, 2017 Tower Observation \& Analysis Report. 